\title{
Analysis of the Present Situation and Countermeasures of Humanistic Quality Education in Medical Colleges and Universities
}

\author{
Mi Feng \\ Qiqihar Medical University \\ Qiqihar Heilongjiang Province 161000
}

\author{
Song Yaoxin* Corresponding author \\ Qiqihar Medical University \\ Qiqihar Heilongjiang Province 161000
}

\begin{abstract}
This paper mainly studies the shortcomings of domestic higher medical colleges in the practice of humanistic quality education, analyzes the problems in its quality and the causes for the hard speeding up and lagging behind. With reflection and construction as the research paradigm, explore an effective way that meets the actual need of the humanistic education in China's medical colleges and universities. To optimize the system structure of students' quality education, promote the richness and integrity of humanities education, strengthen its construction and implementation, and improve the quality through development.
\end{abstract}

Keywords-Medical school; Humanistic quality; Education status quo; Analysis of countermeasures

\section{The Present Situation of College Students' HUMANISTIC QUALITY}

Humanistic knowledge is the theoretical support of humanistic quality education, while the latter is based on scientific and systematic humanistic knowledge. But I found that modern college students, especially who are major in science and engineering, show little interests in philosophy, history, literature, art and other aspects of humanities. They would rather spend time on the game, gossip than read world-famous books. Although the knowledge sources are rich and varied, the part of the humanities knowledge is blank, resulting in their inability of speculative thinking. They know no history or culture of their own country, to say nothing of the foreign ones. The external temperament and conservation will not be excellent without inner nourishment of literature and art. The common problem in the current college students is a serious lack of humanistic knowledge. Through decades of reform and opening up, great achievements have been made in China's economic development, however, spiritual civilization achievements are not commensurate with that. The imbalance reflects particularly on the shortness of educational resources in poverty-stricken areas, regional inequity in education resources, discouraging many people who are determined to carry out humanistic quality education.

This article is the research production of Heilongjiang Provincial Philosophy and Social Sciences Research and Planning Project "Higher Medical College medical humanities quality training model reform research", approval number: 17EDD180

\section{NEW STUdy OF HUMANISTIC EDUCATION IN COLLEGES AND UNIVERSITIES}

\section{A. The Background of the Development of Humanistic Education}

To improve the comprehensive level of higher education in our country, we must attach importance to the humanistic quality education which is a weak link of higher education system in our country. The quality of humanities has a great influence on the future and destiny of college students, and its importance is no less significant than the importance of professional quality education to college students, and even has a close link with social harmony and the country's long-term stability. Since the beginning of this century, the voice that the school should cultivate complex talents has been louder and louder. For colleges and universities, it is an educational problem facing all teachers that how to cultivate well-rounded talents that can adapt to the rapid development of social requirements educational problems. We need to strive persistently in exploration in just a few years to make up for nearly two decades of lack of humanistic quality education. A high quality talent should possess high-level professions, and the higher quality of humanities to match with that. A person's humanities quality cultivation can affect his whole life and career.

\section{B. Factors Restricting the Humanities Education}

Since quality education refers to not only professional orientations but also humanities without which quality education will be incomplete and unscientific. The importance of humanistic education in the domestic institutions of higher learning remaining at the very outset has not obtained wide acknowledgement. With a low starting point and little momentum, its development is beset with twists and turns and often makes way for other projects.

Under the influence of various factors, the domestic colleges and universities have been pursuing the professional quality as the primary assessment indicator of personnel training at the expense of humanistic cultivation, which is apparent on science and engineering students in particular. [1]Due to the impact of commodity tide and the limitation of social and historical conditions, people in the domestic institutions of higher learning put emphasis more on professions and less on humanities. They offer courses that mainly develop students professional ability and aim at 
"employment" and "money- earning", yet miss the "time consuming" humanistic quality education, thus it is difficult to cultivate well-rounded talents.

The humanities quality education is a systematic project, which is closely related to the traditions, management systems, teachers' strength and students' conditions of colleges and universities. Only when all factors are taken into consideration and the investments increase in real terms, can we establish a perfect humanities quality education system for the students.

\section{Measures of Humanistic Quality Education Improvement}

How to change the plight of humanistic quality education in domestic colleges and universities? This requires us to further deepen the education system reform. And regarding to humanity, we need to be committed to the improvement of education system, the pursuit of innovative teaching methods and higher teaching standards of teachers, as well as stimulate students to learn the humanities and beautify the campus human environment. In higher education, it is necessary to pay attention to the imparting of professional knowledge, at the same time, not to neglect the cultivation of college students' humanistic quality. Therefore, it is the greatest goal for current college education reform to establish, through the expansion, merger and other means, a number of comprehensive university laying equal stress on both literary and arts, profession and humanity.

\section{The Present Situation of the Medical Students' HUMANISTIC QUALITY EDUCATION}

The study of humanistic quality education in higher medical colleges started from the 1990s. Academics began from the study of core courses, then move to in-depth discussion on how medical colleges and universities arrange class teaching, practicing, campus culture cultivation and other issues around the medical humanities. Since the 21st century, the domestic research on this subject has been classified into the following two aspects. First, the theoretical research, which results are mainly concentrated on the medical humanities education connotation and extension, the cultivation of medical humanistic spirit, the establishment of medical humanities education system. And a number of high levels of research results have been achieved in the ecological outlook of the coordinated development of scientific education and humanistic quality, experience and enlightenment from Western developed countries, as well as medical humanities education classroom teaching, etc. Second, the research of practicing. It mainly focuses on medical ethics, doctor-patient relationship, medical disputes, the humanistic spirit in clinical practice, as well as problems and solutions of medical humanities quality education, the education model and so on, delivering a series of high standards of research fruits. [2-3]

\section{A. The Weaknesses of Humanistic Quality Education Research in Higher Medical Colleges}

There are still many weaknesses in the study of humanistic quality education in higher medical colleges. The top-level design is insufficient and the education model that can be promoted and popularized needs improving. The research of practice teaching is not deep enough and without workable research results. The training teaching research is inadequate.
Without independent system, medical humanities curriculum design is not systematic, having no key points and continuity. The future development trend towards humanistic quality education research in domestic higher medical colleges should be the study of humanistic quality education in modern sense, reform the subject setting, and innovate the curriculum system of humanistic quality education. Attention should be paid to the connection with international medical education, and the research in humanities and social sciences and natural science so as to coordinate scientifically the relationship among the various disciplines. We also need to stress on researches of humanistic quality education system, organizations, and humanistic quality education teachers.

\section{B. Problems in Medical Humanities Education in Medical Colleges and Universities and Causes for Its Backwardness}

There are always confusions between some pairs of relevant concepts, like the humanities and medical humanities, humanities education and medical humanities education, humanities science and humanities social sciences and medical humanities. There are some related theories that need further discussion, such as human comprehensive development theory, multiple intelligence theory, and behaviorist learning theory, cognitive constructivism learning theory, humanistic learning theory, and cultural consciousness theory and so on.

There are several reasons for the relative long-term lag of medical education. 1. Before entering the higher medical colleges, college students have never received systematic humanistic quality education in primary and secondary schools; instead, they have long been exposed to the exam-oriented education. 2. The emphasis of profession and overlook of humanity in a long period did not bring a sound, scientific humanistic education system, and teaching strength is weak with the low level of teachers 3. Generally, medical colleges and universities prefer to a rigorous, scientific, realistic attitude of learning, while lacking a relatively thick cultural atmosphere. In such conditions, students themselves also do not attach importance to human learning. 4. The academic research of medical humanities quality education has long been lagging behind. [4-5]

\section{THE REASONS ANALYSIS AND RECOMMENDATIONS ON THE HARD IMPROVEMENT OF MEDICAL STUDENTS HUMANISTIC EDUCATION SYSTEM}

\section{A. Problems in Medical School Humanities Education Pattern}

The problems existing in the pattern of humanistic education are mainly reflected on the background of the times, education system, training process, ideology, principle, goals, the system construction as well as the dynamic, operation, security and the evaluation mechanism. The education and teaching process lack notions regarding innovative spirit, humanistic care, humanistic knowledge application ability and collaboration spirit and the verification of the scientificity and validity of these contents is difficult. That needs us to find out the gap between domestic medical humanities quality education standard and the international advanced level, and establish security, evaluation systems of medical humanities 
quality education model. At the same time, we should demonstrate the rationality and feasibility of these issues.

\section{B. To Clarify the Related Principles, Goals and Systems of Medical Humanities Education}

The principle of medical humanistic education is the unification of unity and individuality; hierarchy and three-dimensional multi-dimensionality; general aim and phased-aims, with medical ethics at its core.

We need to help medical students foster noble medical values, a correct understanding of the relationship between medicine and society, so that they can retain high medical ethics. With humanistic quality education knowledge and methods, we intend to enhance their vocational skills, innovation and management ability with team spirit. With the holistic quality-oriented education ideas in mind, we must strengthen the top design and set a scientific talent training objective. It is our responsibility to strengthen the discipline construction of medical humanities and consolidate the practice system. The last but not least thing is to build the security, evaluation systems for the better maintaining of medical humanities and cultural atmosphere.

\section{To Explore an Effective Way to Meet the Needs of Humanistic Education in Higher Medical Colleges and Universities in China}

Effective measures must be carried out for the concept changing and level rising of teachers who are engaged in the course. The investigation and research should be conducted in multiple dimensions, from the medical personnel training, academic exchanges to inter-college collaboration, in a bid to improve the overall quality and receive actual effect of humanities quality education in China's higher medical college. We should study the effectiveness of medical humanities education in domestic medical colleges and universities, as well as draw lessons from the success in United States, Japan and the United Kingdom. In addition, we need go further to find out the similarities and differences between medical humanities education in Chinese and foreign countries, and make analyses in an all-round way. By doing so, we can put forward the available countermeasures and suggestions to improve the quality of medical humanities education.

\section{To Solve Practical Problems out of Traditional Research Field, Converse Research Perspective out of the Stereotype.}

The quality improvement of medical humanities education not means that the medical science theory and clinical skills are no longer the teaching key points. Without the superb medical science and technology and clinical level, humanistic spirit, humanistic care are like passive water, rootless wood that can't advance or even sustain long. The same is that they can't save the patient's life or relieve their pains. Shaped under different national conditions, traditional cultures, national characters and other factors, medical humanity in different regions is with various features. Being that, we can take as reference rather than copy the pattern of European and American countries. The humanities education and humanistic quality of medical students are based on the further clarification of difference and connection among humanities education, general education and ideological and political education. The grade of humanistic education can't be evaluated by test scores, skill assessment or thesis defense, instead, it is subject to the subjective and qualitative evaluation by the patients served by the medical students, and family members, hospital, community and society that witness their behaviors.

\section{CONCLUSION}

It sheds light on the plight of the development of humanistic quality education in higher medical colleges and universities in China, and helps us establish a teaching mode to improve the quality of medical humanistic quality education. As a reference for the reform of medical humanities education system, it also enriches the theories of medical humanities education. Through the optimization on system the reasonability of the pattern of students' quality education, we can make progress in promoting the richness and integrity of humanities education in medical colleges and universities, and strengthening the setting and implementation of medical humanities in an effort to promote the development and improve the quality.

\section{REFERENCE}

[1] M. Harvard Committee. General Education in a Free Society, translator Li Manli, Peking University Press, 2010.(In Chinese)

[2] M. Xie Boshen. General Medical Education, National Taiwan University, College of Medicine, 2006. (In Chinese)

[3] M. Zhang Daqing. Chinese Medical Humanities Education, Peking University Medical Press, 2006. (In Chinese)

[4] M. Cohen. Authur A. Humanistic Education and Western Civilization. New York: Holt Rinehart and Winston Inc. 1964. (In Chinese)

[5] M. Mirko D. Grmek. Western medical thought from antiquity to the Middle Ages. Harvard University Press, 1998. (In Chinese) 